\title{
Jogando com o patrimônio nas aulas de história
}

\author{
Jugando con el patrimonio en las clases de historia
}

Playing with equity in history lessons

\begin{abstract}
Resumo
O trabalho pretende socializar os percursos de formação constituídos com alunos dos Cursos de Licenciatura em Pedagogia e História, da Universidade Federal do Pampa/Campus Jaguarão. Apresenta como metodologia um inventário em forma de registros das memórias biográficas dos egressos acerca de suas vivências e aprendizagens nas aulas de história, durante o Ensino Fundamental, seguida de uma pesquisa posterior com professores das escolas públicas da cidade de Jaguarão contemplando as realidades e as demandas apresentadas à docência, bem como temáticas históricas. As inferências levantadas acrescentaram ao debate discussões relacionadas à introdução dos jogos para ensinar e aprender história dentro e fora da sala de aula tema recentemente incorporado aos estudos deste campo em específico, repercutindo na elaboração de jogos e materiais didáticos com o enfoque na memória e no patrimônio cultural desta cidade elevada à categoria de Cidade Histórica devido ao significativo repertório patrimonial que reúne. Dentre os resultados do processo coletivo envolvendo práticas e estratégias de ensino, ressaltam-se o exercício da autoria na criação de um repertório de jogos voltados para a construção de conhecimentos e ressignificação da história local a partir do compartilhamento de saberes/fazeres entre a academia e as realidades das instituições educativas e de salvaguarda da memória.
\end{abstract}

Palavras- chave: Ensino de história; jogos; patrimônio cultural

\section{Resumen}

El trabajo pretende socializar los itinerarios de formación constituidos con alumnos de los Cursos de Licenciatura en Pedagogía e Historia, de la Universidad Federal de Pampa / Campus Jaguarão. Se presenta como metodología un inventario en forma de registros de las memorias biográficas de los egresados acerca de sus vivencias y aprendizajes en las clases de historia, durante la Enseñanza Fundamental, seguida de una investigación posterior con profesores de las escuelas públicas de la ciudad de Jaguarão contemplando las realidades y las demandas presentadas a la docencia, así como temáticas históricas. Las inferencias levantadas añadieron al debate discusiones relacionadas a la introducción de los juegos para enseñar y aprender historia dentro y fuera del aula tema recién incorporado a los estudios de este campo en específico, repercutiendo en la elaboración de juegos y materiales didácticos con el enfoque en la memoria y en el patrimonio cultural de esta ciudad elevada a la categoría de Ciudad Histórica debido al significativo repertorio patrimonial que reúne. Entre los resultados del proceso colectivo involucrando prácticas y estrategias de enseñanza, se resaltan el ejercicio de la autoría en la creación de un repertorio de juegos orientados a la construcción de conocimientos y resignificación de la historia local a partir del compartir de saberes / hacer entre la academia y la escuela, las realidades de las instituciones educativas y de salvaguardia de la memoria.

Palabras clave: Enseñanza de historia; juegos; patrimonio cultural

\footnotetext{
Abstract

${ }^{1}$ Mestre e Doutora em Educação pela UFRGS. Professora do Curso de Bacharelado em Produção e Política Cultural da Universidade Federal do Pampa- Campus Jaguarão; hildajaqueline7@ gmail.com
} 
The work intends to socialize the training courses constituted with students of the Courses of Degree in Pedagogy and History, Federal University of Pampa / Jaguarão Campus. It presents as an methodology an inventory in the form of records of the biographical memories of the graduates about their experiences and learning in the history classes, during Elementary School, followed by a later research with teachers of the public schools of the city of Jaguarão contemplating the realities and the demands presented to teaching, as well as historical themes. The inferences raised added to the discussion discussions related to the introduction of games to teach and learn history inside and outside the classroom theme recently incorporated into the studies of this field in specific, repercussion in the elaboration of games and didactic materials with the focus on memory and equity cultural center of this city elevated to the category of Historic City due to the significant patrimonial repertoire that reunites. Among the results of the collective process involving teaching practices and strategies, we highlight the exercise of authorship in the creation of a repertoire of games aimed at building knowledge and re-signification of local history through the sharing of knowledges between the academy and the realities of educational institutions and the safeguarding of memory.

Keywords: History teaching; games; cultural

\section{Introdução}

Este artigo pretende socializar ações no âmbito da Educação para o Patrimônio, levadas a cabo por discentes dos Cursos de Licenciatura em Pedagogia e História da Universidade Federal do Pampa/Campus Jaguarão enquanto proposta de formação ligada aos componentes curriculares: Ensinar e Aprender História e Estágio Supervisionado III Educação em Espaços Não Escolares. Os percursos dessas vivências originaram jogos e materiais didáticos para o ensino de história com enfoque na memória e no patrimônio cultural desta cidade elevada à categoria de Cidade Histórica, devido o significativo repertório patrimonial que remonta aos séculos XVIII e XIX, período de grande desenvolvimento econômico na região decorrente da produção do charque.

A obtenção do título e a inserção da cidade de Jaguarão no Programa Federal - PACCidade Históricas atrelada às reformulações curriculares dos cursos de licenciatura previstas pela LDB e os PCNs, serviram de mote para a incorporação, em ambas as disciplinas, de discussões teóricas-metodológicas substanciadas na compreensão do patrimônio como uma categoria importante para a reflexividade dos fazeres/saberes dos professores em formação e para o ensino de História no Ensino Fundamental. Sobretudo, quando o objetivo consiste em compor novas formas de ensinar e aprender História numa cidade histórica, considerando os desafios que se apresentam à Educação para o Patrimônio nesses contextos, em especial, os que correspondem especificamente às abordagens do patrimônio para ensinar e aprender aspectos da História Local e a função educativa das instituições que salvaguardam a memória, quase sempre ancorada na celebração e espetacularização de uma narrativa historicista pautada no protagonismo de determinados grupos na história das cidades e, consequentemente, na operação da noção homogênea do patrimônio Guimarães (2015). Perante a necessidade de um aprofundamento deste debate como um eixo importante das 
relações e processos de fazer-se professor de história, às discussões feitas em aula adotaram como percurso, num primeiro momento a análise dessas problemáticas na realidade do ensino de história nas escolas de Jaguarão nos Anos Iniciais e nos Anos Finais colocadas num segundo momento em diálogo com as memórias das aulas de história dos discentes de ambos os cursos de licenciatura.

As inferências levantadas acerca desta aproximação sinalizaram várias questões a serem consideradas, dentre elas a evidência do que Guimarães (2015) define de ritualização de uma "colonização do presente pelo passado" na história das cidades. As análises das operações dessa colonização verificadas em Jaguarão possibilitaram visibilizar parte de suas implicações pedagógicas na História ensinada e aprendida por crianças e jovens nas escolas e nas atividades patrimoniais levadas a cabo por agentes culturais. Na mesma medida, abriram espaço para a percepção de indícios de memórias, sensibilidades e experiências históricas compartilhadas de diferentes grupos sociais, mostrando distintas formas de existência e resistência inscritas no espaço urbano ao longo de sua formação histórica.

Os sentidos outros, levantados pelas experiências pregressas e recentes vivenciadas pelos professores das escolas locais e alunos egressos constituiram a criação de percursos metodológicos com o objetivo de reorientar as percepções, práticas e compreensões acerca da história e o seu ensino utilizando como mote leituras e interpretações históricas das cidades atentas aos mecanismos de controle social e político da memória, bem como de existência e resistências históricamente invizibilizadas na urbe.

De acorco com Ciampi (2015, p. 68) pensar e concretizar políticas associadas ao ensino de história sob estas premissas significa não ignorar as questões ideológicas que envolvem a construção dos patrimônios e o silenciamento deliberado de determinadas experiências e práticas culturais que requerem a ampliação da noção de patrimônio no currículo da disciplina considerado hodiernamente em sua diversidade e consequentemente, nas suas dimensõesem em termos de direitos humanos e culturais.

Com base nestas inferências a elaboração de jogos didáticos envolvendo as temáticas: Patrimônio, História e Memória local e a formulação de práticas educativas em lugares de memória da cidade buscou alterar relações e aprendizagens históricas consensuais e nataturalizadas pelo currículo das escolas. Os materiais e iniciativas foram pensados de maneira a propor situações de aprendizagem histórica com o objetivo de tencionar as permanências de um currículo centrado num ensino da História factual e etnocêntrica assentado na sacralização dos bens de "pedra e cal" ancorados no conceito de aprendizagem que segundo Schimidt (2008) consiste em fazer como que alunos/as ampliem suas 
competências, encontrando significados e localizando-se no tempo, modificando seus modelos e padrões de interpretação histórica.

Amparados nesta noção e nos recentes estudos de pesquisadores do campo do ensino de história sobre o potencial educativo dos jogos na sala de aula discorremos nesta escrita o processo esboçado.

\section{Produzindo novos sentidos para aprender e ensinar história: Patrimônio e História} Local

Nos últimos anos, a História Local tem sido focada com maior intensidade pelos estudos na área do Ensino de História. De acordo com Cerri (2008) e Bittencourt (2004), a valorização da História mais ligada ao tempo presente se sustenta pela possibilidade de compreensão das realidades nas quais os alunos e professores convivem mais diretamente, convertendo-se em objeto de estudo e de aprendizagem histórica capaz de situar o confronto com problemas significativos pertinentes ao ensino, educando para a percepção da existência de historicidades que escapam à lógica de uma suposta "verdade histórica".

Por outro lado, ambos atentam para alguns elementos que caracterizam a maioria das abordagens do ensino da História Local, particularmente no que diz respeito à indispensável superação do mero localismo recorrente nesses estudos e ao papel do ensino de História na configuração das identidades dos alunos. Para os dois autores, o trabalho com a História mais próxima, no contexto escolar, acaba muitas vezes se efetivando nas mesmas premissas da História nacional ao privilegiarem valores, referenciais culturais e a história do poder local de setores dominantes nos municípios.

Acerca desses impasses colocados à docência, Bittencourt (2004) menciona que é preciso identificar quais ênfases e abordagens podem ser incluídas e trabalhadas de modo que a História Local ensinada oportunize a criação de conexões com as experiências vividas de professores, alunos e comunidade nas relações presente/passado/presente. Cerri (2008) acrescenta ainda que é fundamental que elas sejam ao mesmo tempo críticas e alternativas, permitindo um paralelo entre o que chama de artificialidade da História construída e a da Memória, esta última relacionada à experiência dos sujeitos.

$\mathrm{Na}$ esteira destas contribuições, o trabalho com a Memória da cidade insere o Patrimônio Cultural como temática a ser explorada pelas práticas de ensino como fontes históricas não escritas a serem indagadas, desconstruídas e ampliadas em suas funções e usos e educativos, a fim de obter a relevância social para o ensino da História Local (CIAMPI, 2015, p. 68). 
Os desafios desta mediação fazem-se sentir nas formas de aprender e ensinar História em espaços escolares e não escolares de Jaguarão, com os quais se interagiu durante os semestres de 2015/01 e 2016/02. Implantada à margem esquerda do rio que lhe empresta o nome, a cidade localizada em um território de fronteira, historicamente zona de disputa das Coroas Ibéricas, foi essencial para a ocupação portuguesa no Continente de São Pedro. Isso explica sua origem a partir da instalação da guarda espanhola "Fortin de la Laguna", fundada em 1792 e projetada pelo alferes de fragata e cartógrafo espanhol Joaquim Gudim (HORTÊNCIO; LUZ, 2010, p. 6), tomada em 1802 pelas forças lusitanas e denominada Guarda da Lagoa do Serrito.

Os antecedentes históricos levaram à conformação de uma sociedade que se constitui na comunicação e no intercâmbio com a banda oriental, para além das lutas territoriais, com característica eminentemente agrária baseada em grandes extensões de terras que formariam as estâncias e consolidariam uma economia baseada na criação do gado bovino e na intensa produção do charque produzido nas charqueadas instaladas às margens do rio Jaguarão e de seus afluentes, reportando à significativa presença escrava na região.

A sedimentação dessa origem histórica associada à concepção de fronteira como espaço de constante separação e belicosidade entre lusitanos e platinos permite identificar discursos e representações coletivas na História Local, na qual sobressai o "heroismo" típico dos "filhos" da terra, difundido como motivo de orgulho pela população, aludindo à "bravura" e ao caráter "destemido" de seus primeiros povoadores em tempos idos, representados por fazendeiros, charqueadores e oficiais militares. (CRUXEN, 2011, p. 67).

A permanente ritualização da memória coletiva sobre a emblemática e inesquecível resistência de seus moradores na lendária invasão uruguaia de 27 de janeiro de 1865, comandada pelo coronel Manuel Pereira Vargas, rendendo-lhe o título Jaguarão/Cidade heróica, contribui para isso, além, é claro, da imagem construída em torno da obstinação desses vultos na formação de um povoado surgido em meio a tantos conflitos e adversidades, explicando a citação de seus nomes nas ruas e praças e em obras de memorialistas locais.

Percebe-se, portanto, a permanente colonização do presente pelo passado, enfatizada na primazia e no direito à cena pública de uma elite local e regional, assim como seus efeitos na produção de parcialidades históricas segregadoras e excludentes quanto à participação de mulheres, negros, trabalhadores do campo etc.

Kuhn (2007 apud CRUXEN, 2011) destaca algo que parece importante para entender como essas ideias colonizadoras são forjadas num território de fronteira, servindo de elemento elucidativo em direção da compreensão dessas mediações para o âmbito do ensino. Segundo o 
autor, a constituição desta imagem épica e idealizada do conquistador e colonizador para evocar a história da região está atrelada à tradição de uma historiografia cuja concepção de fronteira se institui por meio da excessiva ativação de discursos sobre disputas e supressões entre hispânicos e lusitanos em territórios meridionais.

$\mathrm{Na}$ Jaguarão do presente é possivel constatar como tais ideias colonizadoras são mediatizadas em torno da "Cidade Heroica", atuando nas escolas e em lugares de memória, como bem expressaram os memoriais descritivos propostos aos alunos nas disciplinas da área de Prática de Ensino, como uma primeira atividade de escrita reflexiva tratando das "lembranças/esquecimentos" nas aulas de História no tempo em que eram estudantes.

As memórias registradas e socializadas demonstraram formas de ensinar e aprender História em territórios de fronteira criadas e recriadas em meio a permanências e rupturas experienciadas em sala de aula e em atividades extracurriculares.

As recorrências verificadas nos registros indicam vivências no ensino de História em que a colonização do presente pelo passado se efetiva mediante os seguintes aspectos:

* noção da História como sucessão de fatos e nomes de heróis, e não como processo;

* centralidade do livro didático (quase sempre defasado e com perspectivas etnocêntricas e eurocêntricas), manuais;

* instrumentalização e padronização do fazer docente;

* a defasagem na formação dos professores;

* produção de ausêncisa e/ou a recorrência de representações estereotipadas de indígenas, negros e mulheres;

* pouco ou nenhum espaço para o debate e problematizações.

Quanto às atividades extracurriculares, os memoriais acentuam o quanto as mesmas foram escassas, bem como superficiais as reminiscências tratando de contatos com instituições de memória e os bens culturais da cidade ou região durante a escolaridade. Outro contato ressaltado nos memoriais foram as "famosas" visitas aos pontos históricos de Jaguarão, centradas nos bens culturais consagrados e localizados na zona central. Somam-se às recordações sobre atividades como o desenho deles em um grande painel da turma no retorno à escola. Os registros dessas interações lançaram reflexões antes não cogitadas acerca da existência de outros bens e lugares históricos significativos para além dos já conhecidos e a percepção do quanto o que muitas vezes é considerado patrimônio é construído em meio a relações de poder. Assim, os critérios utilizados para sua definição decorrem sob essas e outras premissas que os instituem enquanto tal. 
As reminiscências trazidas pelos discentes permitiram um "inventário" de práticas pedagógicas engendradas às determinações teóricas, metodológicas e curriculares e, também, às trajetórias e memórias de sujeitos sociais acerca da História e de seu ensino, muitas vezes sustentadas pela colonização de saberes e noções normativas sobre o que deve ser preservado, lembrado e/ou esquecido nas cidades.

Todavia, elas podem ser colocadas em confronto, abrindo-se para outras significações e sentidos sociais e, consequentemente, para uma aprendizagem histórica disposta a desinstalá-las ao renovar percepções e interesses pela(s) história(s) e patrimônio(s) local/locais preocupados com a formação da consicência histórica de professores e estudantes.

Os percursos das reflexões provocadas por essa escrita reflexiva inicial suscitaram o retorno ao cotidiano escolar, "lócus", dos espaços e tempos das aprendizagens para observação e pesquisa sobre a situação do ensino de História e da formação dos professores nos anos iniciais e finais do Ensino Fundamental, através de roteiros e questionários construídos a partir dos memoriais descritivos.

O retorno à sala de aula anos depois, na condição de futuros professores, foi mesclado pela constatação de rotinas já conhecidas e por algumas práticas diferenciadas cotejadas por demandas de um ensino de História em permanente construção/descontrução. As entrevistas feitas com os professores da rede pública de ensino levantaram vários indicadores relacionados ao ensino de História, ao patrimônio e aos lugares de memória como objetos e temas de estudos, carência de novas metodologias e materiais didáticos e formativos, principalmente para o trabalho com a História Local. Afetados por essas memórias e sensibilidades, fomos desafiados a pensar novos sentidos para ensinar e aprender História com e a partir dos patrimônios, extrapolando as "fronteiras" colocadas à formação e ao ensino de História nas realidades escolares e aquelas que separam e/ou fragmentam os saberes gerados na universidade e fora dela (escola e aparelhos culturais) para, com e através delas, instaurar outras formas de conhecer, ensinar e produzir História em cidades históricas.

Para isso, propomo-nos a "jogar" com a História e o Patrimônio levantando "pistas" e "indícios" em lugares de memória para interpretações históricas e patrimoniais ainda não experimentadas nas aulas de história das escolas. Do "jogo" entre os campos da História e do Patrimônio surgiram trilhas, dominós, jogo da memória e tabuleiro, além da consecução de atividades voltadas à Educação para o Patrimônio em instituições culturais, envolvendo a abordagens sobre a História Local considerando as questões étnicorraciais, leituras da paisagem e do patrimônio urbano em diferentes tempos, conceitos e noções patrimoniais, entre outros, amparados no que Pelegrini (2009) apresenta como um dos desafios lançados 
aos professores em formação e em exercício, acerca do planejamento de atividades didáticopedagógicas com este fim, qual seja, o de organizar e criar iniciativas que fujam dos usuais procedimentos de ensino, apoiados essencialmente em livros didáticos e em situações restritas à sala de aula e/ou às bibliotecas das escolas.

Acrescente-se, ainda, o fato de tal perspectiva postular a favor de uma formação que reconheça e exercite a capacidade de autoria dos professores, permitindo-lhes repensar suas práticas a partir também de suas experiências pessoais e profissionais, rompendo "con el aislamiento impuesto por un sistema educativo ocupado cadavez más en imponer racionalidades, eficacias y eficiencias". (Cadernos - Expedición Pedagógica Nacional en Colômbia, 2005, p.20).

Nesses termos, o planejamento dos jogos e das ações educativas ancorou-se nos indicadores retirados da interação entre Universidade e Escola, referenciais gerados por pesquisas recentes na área do Ensino de História, contato com acervos disponiveis nas instituições de memória da cidade (museu, arquivos), obras de memorialistas e de historiadores, definição de material para a confecção dos jogos e ações educativas e criação do "layout". Os resultados e as intenções de cada um desses materiais serão expostos a seguir.

\section{Jogando com os saberes fora e dentro da sala de aula}

"Ensinar é simbolicamente jogar com o conhecimento, mesmo que a ludicidade esteja ausente das nossas proposições pedagógicas, uma vez que sempre nos vinculamos epistemologicamente ao escolher a forma e o conteúdo de nossas aulas". (MEINERZ, 2013, p110)

Ao longo da trajetória do nosso trabalho como professores a preocupação em tornar nossas aulas e aprendizagens significativas e instigantes aos nossos alunos é uma questão frequente.

No que tange o ensino de história especificamente, este debate tem se adensado contribuindo para a consolidação de um campo fértil de saberes/fazeres, impactando a formação de professores e o interesse de pesquisadores da educação.

Referente à introdução de jogos nas aulas de história, estudos recentes focados em análises de práticas de ensino pautadas em novas linguagens e tecnologias de aprendizagem (ANTONI \& ZALLA, 2013, p.149) vem modificando os contornos tradicionais do que convencionalmente definimos como ambiente da sala de aula, quase sempre caracterizada pela centralidade da figura do professor no processo de ensino aprendizagem, a ênfase no conteudismo, na passividade e no desinteresse dos alunos pela história. 
Os resultados destas análises apresentam a sala de aula como um ambiente de interações e experimentações sensíveis nas quais os jogos se constituem enquanto artefatos culturais, na medida em que suas dinâmicas e regras permitem não só a aquisição de habilidades e a capacidade de construir conceitos, como põe em evidência através das suas dinâmicas e regras uma polifonia de aprendizagens e experiências históricas de uma determinada sociedade no tempo, implicando no desenvolvimento de leituras conjunturais capazes de alterar concepções sedimentadas e unívocas acerca do passado que no ato de jogar são colocadas em confronto pelas vivências dentro e fora da sala de aula dos jogadores/alunos.

Desta forma ao considerar o jogo também como artefato cultural, nos propomos jogar com as múltiplas vivências de docentes em exercício e em formação, por entre os percursos desafiantes que o ensinar e aprender história na sociedade contemporânea nos remete, buscando seus novos sentidos, possibilidades de encantamento e encontro de visões de mundo, dimensões potencializadas pelos jogos, sendo que os mesmos estimulam a compreensão e a operação de um saber histórico aberto à diversidade, à inclusão social, à memórias e resistências. A mescla destas trajetórias deu lugar, portanto, à construção de aulas de história em seu sentido lúdico e também epistemológico ao proporem aos professores de história pensar acerca de seus processos de fazer-se professor/a e as suas implicações no campo das políticas públicas nos âmbitos da cultura e educação ao terem como ponto de partida a história local e os bens culturais a ela associados.

Portanto, jogar nas aulas de história deve fazer parte do planejamento da disciplina enquanto forma e conteúdo através do qual professores/ras e alunos/as se assumem como sujeitos da aprendizagem que por ser histórica, tem um compromisso com o seu tempo, no que tange à liberdade e a igualdade de direitos aspectos perceptíveis no processo de confecção dos jogos que apresentamos a seguir.

\subsection{Dominó do Patrimônio}

Este jogo e suas regras funcionam como o tradicional JOGO DE DOMINÓ, que foi elaborado com o objetivo de trabalhar a ideia ampliada de patrimônio de maneira lúdica e interativa, a fim de desnaturalizar percepções sobre o que comumente é definido como bens culturais relevantes para uma coletividade, levar à indagação dos critérios usados para sua 
definição, suas funções e representações para diferentes grupos. As proposições do jogo ${ }^{2}$ buscam, entre outras coisas, potencializar de maneira acessível a noção de "referencialidade cultural" como aspecto importante para a compreensão de que os valores usados para justificar sua preservação e significado social são circunstanciais, ou seja, podem ser modificados pela própria dinâmica da cultura e de novas relações estabelecidas entre os bens culturais e seus tributários.

Munidos dessa intencionalidade, foi necessário que os acadêmicos realizassem um "inventário" atento a esses aspectos, contemplando para a elaboração do jogo a materialidade e a imaterialidade dos patrimônios e a identificação de outros bens culturais fora da zona histórica de Jaguarão.

Os inventários seguidos de pesquisas bibliográficas suscitaram a inserção do patrimônio ambiental, dando origem à criação de um dominó tratando do BIOMA PAMPA. A perspectiva apontada configurou jogos abrangendo imagens e informações que abarcam o patrimônio edificado, as manifestações culturais, ofícios, culinária, lendas, monumentos etc. Como forma de introduzir informações referentes ao jogo, foram inseridos alguns conceitoschave relacionados às medidas de proteção e acautelamento patrimonial, como: PATRIMÔNIO CULTURAL, TOMBAMENTO, INVENTÁRIO, SALVAGUARDA, BENS TANGÍVEIS E INTANGÍVEIS, a fim de propiciar aos alunos o entendimento de suas implicações nas políticas de preservação e gestão do patrimônio e a importância de sua apropriação pela comunidade.

\subsection{Jogo da Memória Paisagens e Patrimônios Urbanos}

Este jogo da memória foi pensado durante uma aula-oficina com os acadêmicos que consistiu em fazer cartografias de diferentes pontos do perímetro urbano: esquinas, ruas, praças nas quais se localizam algumas das edificações históricas da cidade, de modo a aguçar e promover situações de aprendizagem voltadas à observação das mudanças e permanências na paisagem urbana quanto aos seus traçados, disposição de bens culturais, alterações e ecletismo arquitetônico. As cartografias desafiaram a pensar num suporte pedagógico desencadeador de leituras e interpretações patrimoniais utilizando-se de imagens antigas e atuais de determinados lugares e patrimônios conhecidos pela maioria dos moradores.

\footnotetext{
${ }^{2}$ A primeira versão do jogo foi construída pelos acadêmicos Carlos Pacheco Cunha e Zilma Martins, do Curso de História Licenciatura, na disciplina Metodologia de Ensino de História, posteriormente cedida como material para o ensino e adaptada.
} 
O planejamento do jogo suscitou pesquisas em acervos do Instituto Histórico e Geográfico de Jaguarão e do Departamento de Patrimônio Cultural, da Secretaria de Cultura e Turismo. O processo de seleção das fotografias levantou cerca de 20 locais e edificações, compondo 10 pares de acordo com o conhecido jogo de memória. Entre suas finalidades está a de incorporar as fontes imagéticas ao rol dos bens culturais e movimentar sensibilidades e esquemas interpretativos que permitam aos participantes, no jogo de imagens do presente/passado, perceber que a cidade, sua organicidade e seus patrimônios se modificam ao longo do tempo, alterando-se, segundo Guimarães (2015, p. 98), “[...] em franco diálogo com a emergência de novas técnicas e materiais, bem como as delimitações de seus territórios se modificam em íntima sintonia com as relações sociais de produção e interesses de mercado".

Ao propor como foco educativo a interpretação patrimonial da cidade em sua materialidade, a autor salienta de forma mais apurada as marcas deixadas pela ação do homem em interação com os espaços plurais que se moldam, se refazem ao sabor das experiências do presente de seus sujeitos, tornando-se um lugar não só habitado, mas também compartilhado onde podem ser estabelecidas maneiras distintas de interagir com o legado cultural.

\subsection{Trilha Territorialidades Negras em Jaguarão}

A trilha "Territorialidades Negras em Jaguarão" traz como temática a História, a Memória e o Patrimônio sob o enfoque étnico-racial. Discussões atuais do campo do Patrimônio têm levantado estudos nessa direção resultantes de demandas sociais associadas à reivindicação do direito à memória de segmentos excluídos pela História oficial, com destaque para a História e o Patrimônio deste grupo étnico em específico.

As lacunas e informações esparsas sobre os "rastros" deixados por essas experiências, seja na História Nacional ou na História Local, serviram de premissas iniciais para sua sistematização. A elas juntaram-se reflexões acerca da ritualização de ideias colonizadoras que ora invisibilizam tais participações e registros memoriais, ora as visibilizam segundo pontos de vista reducionistas e estereotipados balizados em operações discursivas, assentadas na ótica do colonizador, branco e europeu, que atua de maneira a desconsiderar esses grupos como sujeitos e também produtores culturais no contexto citadino.

Cabe destacar acerca desta tensão entre "presença/ausência" da etnia negra na História e no Patrimônio Cultural das cidades as omissões relativas às práticas culturais e às estratégias de resistência criadas por estas populações, para além da opressão a que estavam submetidas na sociedade escravista. Tais conjecturas e constatações verificadas quanto ao tema na realidade local evidenciaram a pertinência de composição de uma trilha tangenciada por estas 
e outras problematizações. Serviram de escopo para a formulação de seus traçados os artigos de Vargas (2010) tratando da experiência do Museu de Percurso do Negro em Porto Alegre e de Lima e Al-Alam (2013) sobre os territórios negros existentes em Jaguarão. ${ }^{3}$

Partindo dessas coordenadas, fomos à busca das territorialidades difusas cujas artes do fazer repercutiram em um "layout" para o jogo e a formulação de pistas e informações com o intuito de provocar o desmanchamento de fronteiras criadas pelas narrativas monolíticas sobre o tema no passado/presente da cidade. Como marcas dessas presenças, sobressaem no jogo organizado através de imagens tridimensionais os seguintes territórios: PRAÇA DO DESEMBARQUE, MERCADO PÚBLICO, ANTIGA CADEIA PÚBLICA, CHARQUEAdA SÃO JOÃO, O SOBRADO DO BARÃO TAVARES LEITE, PRAÇA DR. ALCIDES MARQUES, CLUBE SOCIAL 24 DE AGOSTO E QUILOMBO MADEIRA.

O funcionamento do jogo abrange pistas e dados de modo a desconstruir consensos naturalizados sobre o tema e levar à descoberta de uma gama de conhecimentos sobre os patrimônios e lugares de memórias destas territorialidades, percebendo que o passado é constituído por muitas leituras que ora incluem, ora excluem determinadas histórias e práticas culturais de uma sociedade (FONSECA, 2003, p. 65), mobilizando por meio dos avanços e recuos dos lances de seus jogadores novos conhecimentos no sentido de entender determinados mecanismos propensos a reproduzir a negação de direitos da etnia negra e problematizar a operação do mito Cidade Heroica, na qual a história desses grupos "parece abdicar" de seu lugar na urbe.

\subsection{Ação Educativa: Procurando "Pistas"}

Procurando pistas trata de uma ação educativa formulada pelos acadêmicos durante as práticas de Estágio Curricular em Espaços Não Escolares que consiste em criar ações de Educação para o Patrimônio em instituições. No caso dessa ação em particular, o campo de inserção foi a Biblioteca Pública Castro Alves. A escolha da instituição deve-se a sua aproximação com o prédio do antigo Mercado Público foco desta atividade. Situado no coração do sítio histórico, além de reportar às histórias do cotidiano da cidade e ao intenso comércio de produtos e escravos no passado, encontra-se em franco processo de restauração e

\footnotetext{
${ }^{3} \mathrm{O}$ artigo trata da oficina com o mesmo título realizada durante a XVII Jornada de Ensino de História e Educação, na Universidade Federal do Pampa-Campus Jaguarão, em agosto de 2011.
} 
planejamento de seu futuro uso e apropriação pelos moradores. As ações de revitalização serviram de detonadores para a proposição de uma mediação educativa em forma de oficina, tratando da memória deste patrimônio significativo da cidade, explorando seus aspectos sociais, culturais e arquitetônicos, bem como o sentimento de pertença, utilizando-se para isso de uma atividade "detivesca" pensada para alunos do 6o ano do Ensino Fundamental, a partir de pistas e informações relacionadas ao Mercado Público. ${ }^{4}$

A oficina tem como objetivos recuperar aspectos da história deste bem cultural no contato com fontes escritas: jornais, decretos, municipais, plantas baixa do prédio, correspondências, livros de registros de vendas de produtos escravos acompanhadas por pistas em forma de "charadas", provocando os participantes a descobrirem do que se trata e a compreenderem um pouco do ofício do historiador.

A ação inicia com a recepção das turmas de alunos para uma breve explicação da atividade, que consiste em formarem inicialmente uma equipe de "detetives" que, através de “indícios", descobrirão o que se está procurando na Biblioteca. Para isso, as equipes criam seus nomes e recebem lupas para lerem e decifrarem essas pistas. Cada equipe recebe seus crachás com numeração, registra o nome escolhido e recebe caixas de acordo com a distribuição das identificações contendo o material.

Após as interpretações das fontes, cada equipe apresenta suas hipóteses e deduções, chegando-se à conclusão que corresponde ao mercado. Trabalham-se noções como fonte, patrimônio e pertencimento, sensibilizando-os para a importância das edificações como monumentos/documentos; daí a relevância de sua preservação e do acesso comunitário. Ressalta-se também que a História não se restringe somente ao espaço da disciplina na sala de aula, na medida em que se pode aprender e "fazer" História em outros espaços da cidade, a exemplo da Biblioteca Pública, também patrimônio cultural.

A mediação é seguida de uma avaliação dos alunos sobre a atividade e encerrada com uma visita para conhecer de perto o patrimônio cultural, em frente ao prédio da Biblioteca. Orientados pelas mediadoras, os estudantes realizam uma interpretação patrimonial do bem, onde são enfatizados detalhes construtivos, estilos e funções pretéritas.

\section{Conclusões}

\footnotetext{
${ }^{4}$ A ação educativa foi elaborada pelas ex-alunas estagiárias Josi Tormam e Nathalia Affonso. Dela surgiu o Projeto de Extensão: Lendo o patrimônio da cidade.
} 
O trabalho coletivo esboçado por professores em formação postas em diálogo com as práticas pedagógicas dos professores em exercício possibilita pensar ações de Educação para o Patrimônio de maneira consequente a fim de (re)criar sentidos novos para a História ensinada alicerçados nos princípios de cidadania e de consciência histórica, de modo a qualificar as políticas públicas para a Educação e a Cultura, não se esquivando, para isso, de tocar em questões que se explicitou anteriormente sobre as tensões entre a História e seu ensino cotejadas pelas discussões do campo do Patrimônio Cultural.

Conclui-se dessas vivências e experimentações relacionadas à formação docente que é também papel dos mestres desnaturalizar percepções acerca dos patrimônios que colonizam o presente na relação com um passado ritualizador de mitos fundadores, transformando as Cidades Históricas em cidades acolhedoras das diversidades e participações culturais que participam/participaram de sua tessitura.

\section{Referências}

BITTENCOURT, Circe Maria Fernandes. Ensino de História: fundamentos e métodos. São Paulo: Cortez, 2004. p. 164-173.

CERRI, Luis Fernando. Cidade e identidade: região e ensino de História. In: ALEGRO, Regina Célia; et al. (Org.). Temas e questões para o ensino de História do Paraná. Londrina: Ed. da Universidade Estadual de Londrina - EUEL, 2008, p.18-37.

CADERNOS - EXPEDICIÓN PEDAGÓGICA NACIONAL EN COLOMBIA: Recreando rutas y senderos pedagógicos: Valle, Cali y región norte del Cauca. Colômbia: Universidad Pedagógica Nacional, 2005. 254p.

CIAMPI, Helenice. Mediações entre ensino de História e Patrimônio. In: ZAMBONI, Ernesta; GALZENARI, Maria Carolina; PACIEVITCH, Caroline (Orgs.). Memória, sensibilidades e saberes. Campinas/SP: Alínea, 2015. p. 64-75.

CRUXEN, Edson Bisso. A ocupação ibérica do território e as disputas pelas fronteiras do continente de Rio Grande. In: CARELI, Sandra da Silva; KNIERIM, Luiz Claudio (Orgs.). Releituras da História do Rio Grande do Sul. Porto Alegre: Fundação Instituto Gaúcho de Tradição e Folclore / CORAG, 2011. p. 65-88.

FONSECA, Maria Cecília Londres. Para além da pedra e cal: por uma concepção ampla de patrimônio cultural. In: ABREU, Regina; CHAGAS, Mário (Orgs.). Memória e Patrimônio: ensaios contemporâneos. Rio de Janeiro: DP\&A, 2003. p. 56-76.

MEINERZ, Carla Beatriz. Jogar com a História na sala de aula. In: GIACOMONI, Marcello Paniz; PEREIRA, Nilton Mullet (Orgs).Jogos e ensino de história. Porto Allegre: Evangraf, 2013, p.99-116. 
GUIMARAES, Maria de Fátima. Patrimônio Cultural e Ensino de História: problematizando a colonização do presente pelo passado. In: ZAMBONI, Ernesta; GALZENARI, Maria Carolina; PACIEVITCH, Caroline (Orgs.). Memória, sensibilidades e saberes. Campinas/SP: Alínea, 2015. p. 90-102.

HORTÊNCIO, Leonardo Marques; LUZ, Maturino S. Santos da. Cidades originadas no processo de consolidação das fronteiras: o caso de Jaguarão. [s.d.]. Disponível em: <http:///www.uniritter.edu..br/eventos/sepesq/vi_sepeq/arquivosPDF/28030/2478/com_identif icação/Jaguar_0\%20-\%20Sepesq\%202010.pdf>. Acesso em: 12 jun. 2012.

LIMA, Andréa de Gama; AL-ALAM, Caiuá Cardoso. Territórios negros em Jaguarão: revisitando o centro histórico. In: GASPAROTTO, Alessandra; FRAGA, Hilda Jaqueline de; BERGAMASCHI, Maria Aparecida (Orgs.). Ensino de História no Cone Sul: patrimônio cultural, territórios e fronteiras. Porto Alegre: Evangraf, 2013. p. 261-272.

PELEGRINI, Sandra C. A. Patrimônio cultural: consciência e preservação. São Paulo: Brasiliense, 2009. 134 p.

SCHMIDT, Maria Auxiliadora. Perspectivas da consciência histórica e da aprendizagem em narrativas de jovens brasileiros. Revista Tempos Históricos, Marechal Cândido Rondon, PR, UNIOESTE, Programa de Pós-Graduação em História e Curso de Graduação em História, v. 12, p. 81-96, 1ํㅗ sem. 2008.

VARGAS, Pedro Rubens. Interpretação do espaço urbano e as possibilidades de leitura da cidade. In: POSSAMAI, Zita Rosane (Org.). Leituras da Cidade. Porto Alegre: Evangraf, 2010. p. 283-296. 